\title{
ARQUIVOS
}

\section{ARROLAMENTO DAS FONTES HISTÓRICAS DO MUNICÍPIO DE TUPÃ (SP).}

\author{
ANTONIO EULER LOPES CAMARGO \\ Licenciado em História pela Faculdade de Filosofia, \\ Ciências e Letras da Universidade Católica de \\ Campinas (S.P.) \\ INTRODUÇÃO.
}

A Revista de História vem publicando, desde o apêlo formulado pelo Prof. Eurípedes Simões de Paula em um de seus primeiros números, numerosos arrolamentos das fonets históricas de cidades do interior do Estado de São Paulo, entre outras São José do Rio Prêto, Laranjal Paulista, Itapetininga, Avaré, Presidente Prudente, Mogí das Cruzes, Pinhal, Jundiai, Batatais, etc.

Empolgado por tantos exemplos e notando falta entre êsses arrolamentos, um de alguma cidade da região da Alta Paulista, propus-me a apresentar êste modesto trabalho sôbre a cidade de Tupã, devido à sua importância na região. Desnecessário dizer da importância dos arquivos para o estudo da História, ainda mais de cidades de fundação recente como as da região, onde ainda podemos alertar as autoridades a fim de preservá-los da destruição, fato não incomum em cidades antigas.

Por último, gostaríamos de agradecer ao vigário-auxiliar da $\mathrm{Pa}-$ róquia de São Pedro de Tupã, o Revmo. Pe. Tito Marega, que nos possibilitou fazer êste trabalho, acolhendo-nos em sua residência.

\section{DADOS GERAIS. SITUAÇÃO GEOGRÁFICA.}

1. - Área territorial: $861 \mathrm{~km}^{2}$.

2. - Posição da sede do Município: Latitude Sul: 210, 56', 00". Longitude W. Gr.: 50', 30', 47".

3. - Distância em linha reta da capital do Estado: $441 \mathrm{~km}$.

4. - Altitude da sede: 511 metros. 
5. - Hidrografia: E' banhado pelos rios Peixe e Feio (ou Aguapeí), e ribeirões Iacri, Sete de Setembro, Pitangueiras e Barreirão (ou Santa Terezinha) entre outros.

6. - Temperatura.

Mínima: 12 graus.

Máxima: 32 graus.

7. - Precipitação pluviométrica: $1.278 \mathrm{~mm}$.

8. - Zona Fisiográfica: O Município está localizado na zona fisiográfica de Marília, limitando-se ao norte com Lusiânia e Santópolis do Aguapeí; ao sul com Rancharia, João Ramalho e Quatá, a oeste com Bastos e Iacrí e a leste com Queirós, Herculândia e Quintana .

9. - População: segundo estimativa de 1968, o município possui 66.671 habitantes.

\section{ASPECTOS HISTORICOS.}

A região onde se instalou o atual município de Tupã não passava de floresta virgem quando Luiz de Sousa Leão, em fins de 1929, escolheu área localizada no traçado da Companhia Paulista de Estradas de Ferro, no espigão dos rios Peixe e Feio (ou Aguapeí), a fim de iniciar a construção da futura cidade de Tupã .

A idéia de edificar a nova cidade nascera da necessidade de um centro-chave entre as zonas Noroeste e Sorocabana. O nome Tupã (o Ser Supremo), foi dado como homenagem aos primtivos donos da terra. Incessante progresso em todos os campos de atividades tem estimulado, desde então, o crescimento de Tupã, graças ao trabalho dos pioneiros que se associaram à obra do fundador e ao inteligente plano de loteamento, pôsto em prática quando da fundação da cidade.

\section{FORMAÇÃO ADMINISTRATIVA.}

O Decreto estadual no 6.720 , de 2 de outubro de 1934 , criou o distrito de Tupã, no Município de Glicério.

O Município surgiu pelo Decreto estadual $\mathrm{n}^{\circ}$ 9.775, de 30 de novembro de 1938, constituído pelos distritos de Tupã e Parnaso, desmembrados de Glicério; Iacrí destacado de Biriguí; Rinópolis de Araçatuba e Bastos, que pertencia ao Município de Marília.

O Decreto-Lei estadual no 14.334, de 30 de novembro de 1944, desmembrou do município de Tupã, os distritos de.Bastos e. Rinópolis, 
transformados em municípios autônomos, e anexou-lhe o distrito de Varpa, foram ao mesmo tempo, contemplados com territórios desmembrados do de Herculândia, perdendo Varpa, no entanto, parte de uma área para o distrito e Município de Quintana .

Pelo mesmo Decreto-Lei, suprimiu-se o distrito de Parnaso, cujo território passou a integrar os distritos de Herculândia e Juliânia transferindo-se, para o distrito e Município de Rinópolis, então criado, parte do território do distrito de Iacrí. Ficou com três distritos: Tupã (sede), Iacrí e Varpa.

A 24 de dezembro de 1948, pela Lei estadual no 233 , criou-se em Tupã o nôvo distrito de Arco-Iris, com território desmembrado do distrito-sede. A 31 de dezembro de 1953, pela Lei estadual $\mathrm{n}^{\circ} \mathbf{2} .456$ é reestabelecido do distrito de Parnaso com território cedido pelo distrito-sede de Tupã.

Mais recentemente, pela Lei estadual no 5.285, de 18 de fevereiro de 1959, foi elevado à categoria de Município e distrito de Iacrí. A mesma lei criou o distrito de Universo, com territórios desmembrados do distrito-sede e de Iacrí.

Atualmente, o Município se compõe de cinco distritos: Tupã (sede), Arco-Iris, Parnaso, Varpa e Universo.

Pelo Decreto-Iei estadual no 49.444, de 8 de abril de 1968, o Município de Tupã foi incluído no Roteiro Turístico do Estado de São Paulo.

\section{DIVISÃO JUDICIÃRIA.}

De 2 de outubro de 1934 a 30 de novembro de 1938, Tupã (então distrito de Glicério) fazia parte do Têrmo de Glicério, pertencente à comarca de Penápolis.

Pelo mesmo decreto estadual n? 9.775, de 30 de novembro de 1938, que elevou Tupã a Município, foi criada a Comarca de Pompéia, com jurisdição sôbre Tupã .

Este Município foi elevado a Têrmo e Comarca pe!o Decreto estadual $\mathrm{n}^{\text {o }}$ 14.334, de 30 de novembro de 1944, com jurisdição sôbre os Têrmos de Tupã, Bastos, Parapuã e Rinópolis.

Por Lei no 5.285, de 18 de fevereiro de 1959, a Comarca foi elevada de 2a. a 3a. entrância, perdendo o têrmo de Rinópolis que passou a Categoria de Comarca. 
Presentemente, a Comarca de Tupã é de $44^{\mathrm{a}}$ entrância, é sede da 19a. Circunscrição Judiciária à qual estão subordinadas as Comarcas de Oswaldo Cruz, Lucélia e Adamantina.

\section{ASPECTOS ECONÔMICOS.}

Município de grande vitalidade econômica, Tupã desenvolve suas atividades nos setores da indústria, do comércio e da agropecuária com a intensidade característica das zonas pioneiras, de rápida expansão.

\section{I. - ARQUIVOS DA CAMMARA MUNICIPAL.}

Localização: Av. Tamoios, $\mathrm{n}^{\circ} 1.153-1 .^{\circ}$ andar.

Presidente atual José Sanchez.

$\mathrm{O}$ arquivo contém:

LIVRO DE ATAS DAS SESSÕES DA CÂMARA MUNICIPAL:

1. - de 01-01-1948 a 17-07-1948.

O primeiro assentamento é a "Ata da instalação da Câmara Municipal de Tupã" de $1^{\text {Q }}$ de janciro de 1948. Diz:

"A primeiro de janeiro de mil novecentos e quarenta e oito, nesta cidade de Tupã, no edifício da Prefeitura Municipal e onde funcionará a Câmara Municipal, às dezenove horas, sob a presidência do Exmo. Sr. Dr. Antônio Rodrigues Pôrto, Juiz Eleitoral de 143a. zona, compareceram os vereadores Trio Spinardi, Anísio Carneiro, Antenor de Barros Leite, João Pedro Ramos, Alberto Cattani, Luciano Fernandes, Alcides Muniz, Olegário Fortes, Francisco Moraes, Pio de Almeida, Oscar Elias Bueno, José Lemos Soares, Oyama de Mesquita Grecco, Massuyuki Kawano, Guilherme Cabral de Moura, João Bento Ferreira, Antonio Caram, Clementino Campos Rocha, José Gavazza, Luiz de Souza Leão e Benedito Moisés. A seguir o Dr. Juiz Eleitoral convidou a mim para secretariar a presente sessão, e passou a examinar os diplomas exibidos pelos vereadores. Verificando estarem conformes os diplomas, e presente, a maioria (ou a unanimidade, digo a maioria dos vereadores eleitos) o Dr. Juiz Eleitoral declarou instalada a Câmara Municipal de Tupã. Em seguida, o Dr. Juiz Eleitoral anunciou que ia proceder-se à eleição da Mesa da Câmara, realizada a votação por escrutínio secreto e voto indevassável, apurou-se o seguinte resultado: $-1^{\circ}$ para presidente Luiz de Souza Leão com catorze (14) votos, Anísio Carneiro, com cinco (5) votos; $2^{\circ}$ para $1 .^{\circ}$ secretário, Alberto Cattani, com dezesseis (16) votos João Pedro Ramos, com dois (2) votos e Oyama de Mesquita 
Grecco com um (1) voto; $3^{\circ}$ para segundo secretário Luciano Fernandes com dezoito (18) votos. Diante dêsse resultado, o Dr. Juiz Eleitoral proclamou eleitos os Srs. Luiz de Souza Leão para presidente, Alberto Cattani para primeiro secretário e Luciano Fernandes para segundo secretário. Finalmente, mandou o Dr. Juiz Eleitoral que se lavrasse esta ata que vai devidamente assinada. Eu, Alberto Cattani - secretário da sessão - a escrevi.

Antonio Rodrigues Porto

José Lemes Soares

Olegário Fortes

José Gavazza

Alcides Muniz

Anísio Carneiro

Oyama de Mesquita Grecco

Clementino Campos Rocha

Antenor de Barros Leite

Massuyuki Kawano

Luciano Fernandes

João Bento Ferreira

Antonio Caram

Trio Spinardi

Francisco Moraes Pio de Almeida

João Pedro Ramos

Oscar Elias Bueno

Guilherme Cabral de Moura

Benedito Moysés

Luiz de Souza Leão

Alberto Cattani".
2. - de 24-07-1948 a 19-05-1949.
3. - de 27-05-1949 a 15-06-1950.
4. - de 15-06-1950 a 20-06-1952 .
5. - de 20-06-1952 a 06-02-1955.
6. - de 06-02-1955 a 28-05-1956.
7. - de 05-06-1956 a 26-09-1957.
8. - de 10-10-1957 a 11-09-1959.
9. - de 10-10-1959 a 02-02-1961.
10. - de 02-02-1961 a 16-04-1962 .
11. - de 16-04-1962 a 26-08-1963.
12. - de 26-08-1963 a 03-08-1964.
13. - de 03-08-1964 a 29-03-1965.
14. - de 29-03-1965 a 06-06-1966.
15. - de 06-06-1966 a 17-04-1967. 


$$
\begin{aligned}
& \text { 16. - de 17-04-1967 a } 06-11-1967 . \\
& \text { 17. - de 06-11-1967 a } 02-09-1968 . \\
& \text { 18. - de 02-09-1968 a } 26-04-1969 . \\
& \text { 19. - de 26-04-1969 a } 24-11-1969 . \\
& \text { 20. - de 24-11-1969 a. }
\end{aligned}
$$

Obs.: - Existem atas das sessões secretas da Câmara, guardadas em pastas lacradas, e só podem ser abertas com decisão da Justiça ou com permissão unânime dos srs. vereadores.

\section{LIVROS DE REGISTROS DE LEIS.}

São 12 livros, assim distribuidos: -

1. - de 31-01-1948 a 20-11-1951.

2. - de 21-11-1951 a 04-11-1954.

3. - de 04-11-1954 a 03-06-1957.

4. $\rightarrow$ de 01-07-1957 a 04-06-1959.

5. -- de 04-06-1959 a 08-03-1960.

6. - de 08-03-1960 a 26-06-1961.

7. - de 26-06-1961 a 05-11-1962.

8. - de 05-11-1962 a 18-11-1963.

9. - de 18-11-1963 a 16-11-1964.

10. — de 17-11-1964 a 21-11-1966.

11. - de 21-11-1966 a 26-12-1967.

12. - de 25-06-1969 a.

O primeiro registro é a Lei $\mathrm{n}^{9} 1$ que trata do impôsto de industrias e profissōes, datada de 31 de janeiro de 1948, sendo presidente da Câmara o sr. Luiz de Souza Leão.

\section{LIVRO DE RESOLUÇÕES INTERNAS DA CÂMARA.}

Um só volume. Iniciado em 12 de janeiro de 1952 ainda está em andamento, sendo que a numeração das resoluções se repetem ano a ano.

\section{LIVRO DE REGISTRO DE PORTARIAS.}

Um só volume. Iniciado em 03 de janeiro de 1948, ainda se encontra em andamento.

LIVRO DE REGISTRO DE EDITAIS E CONCORRENCIA PÚBLICA.

Um só volume. Iniciado em 10 de fevereiro de 1962, ainda está em andamento. 
LIVRO DE TERMOS DE POSSE E REGISTRO DE DECLARAÇÕES DE BENS DOS SRS. VEREADORES.

Um só volume. Iniciado em $1^{9}$ de fevereiro de 1969, estando em andamento.

LIVRO DE REGISTRO DE CONTRÔLE DE VERBAS.

Um só volume. Iniciado em $1^{\circ}$ de fevereiro de 1969, estando em andamento.

LIVROS DE PROTOCOLO DE DOCUMENTOS.

São dois volumes: -

1. - de 04-05-1959 a 24-04-1964.

2. - de 29-04-1964 a.

LIVROS DE INSCRIÇAOO DOS SRS. VEREADORES PARA FALAREM NAS SESSÕES.

São dois volumes: -

1. - de 24-02-1955 a 16-11-1963.

2. - de 03-03-1964 a.

LIVROS DE ASSINATURAS DE PRESENÇA DOS SRS. VEREADORES.

São dois volumes: -

1. - de 24-01-1963 a 26-12-1967.

2. - de 06-01 1968 a.

LIVRO DE REGISTRO DE CORRESPONDENCIA RECEBIDA.

Um só volume. Serve para o registro de tôda correspondência recebida, inclusive jornais e revistas.

Obs.: - A Câmara possui o Indice Geral do Arquivo, organizado em fichário, dividido por ano. Possui também em pastas arquivadas o relatório geral da Câmara, onde se faz o histórico das legislaturas.

O atendimento por parte do sr. diretor da Secretaria da Câmara Municipal foi ótimo, inclusive nos fornecendo informaçōes sôbre a cidade, mas por questão de modéstia não quiz que seu nome constasse neste trabalho.

\section{II. - ARQUIVO DA PREFEITURA MUNICIPAL.}

Local: - Praça da Bandeira.

Prefeito atual: - Walter Pimentel (1969-1972). 
Secretário atual: - Aristin Fernandes.

$\mathrm{O}$ arquivo contém: - -

\section{LIVROS DE LEIS.}

1. - de 28-08-1947 a 11-09-1951.

A primeira lei data de 28 de agôsto de 1947 e trata de concessão de um auxílio financeiro ao tesoureiro da Prefeitura.
2. - de11-09-1951 a 11-05-1956.
3. - de 17-05-1956 a 11-03-1959.
4. - de 11-03-1959 a 12-02-1960.
5. - de 12-02-1960 a 15-09-1962.
6. - de 15-09-1962 a.

\section{LIVROS DE REGISTROS DE DECRETOS-LEI E DECRETOS.}

Contém os decretos-lei e decretos promulgados na época do Estado Nôvo e após essa época.

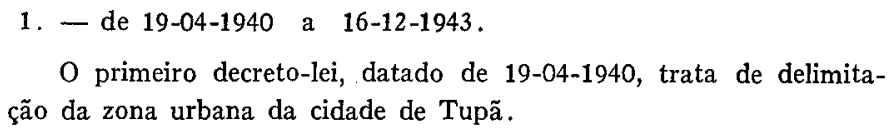

O primeiro decreto-lei, datado de 19-04-1940, trata de delimitação da zona urbana da cidade de Tupã.

$$
\begin{aligned}
& \text { 2. - de 16-12-1943 a } 26-12-1945 . \\
& \text { 3. - de 26-12-1945 a } 25-04-1950 . \\
& \text { 4. - de 03-05-1950 a } \\
& \text { 5. }- \text { de 26-11-1954. } \\
& \text { 6. - de 20-08-1954 a } \text { a } 20-08-1958 \text { a } \\
& \text { 7. - de 05-07-1965 a. }
\end{aligned}
$$

\section{LIVRO DE DECRETO-LEI.}

Um só volume destinado a registrar os decretos-leis promulgados pelo Sr. Prefeito Municipal quando a Câmara Municipal deixar de votar leis pela decorrência de prazo.

\section{LIVROS DE PORTARIAS.}

$$
\text { 1. - de 02-01-1939 a 23-01-1948. }
$$

A primeira portaria trata da nomeação do Sr. Antenor Vieira de Sá, para o cargo de Fiscal Arrecadador do Distrito de Bastos, sendo Prefeito o Sr. Arthur Fernandes da Conceição Santos, sendo datada de 2 de janeiro de 1939.
2. - de 05-02-1948 a 30-07-1958.
3. - de 30-07-1958 a 04-12-1964.
4. - de 14-12-1964 a. 


\section{LIVROS DE ATAS.}

1. - de 08-11-1941 a 07-11-1960.

A primeira ata datada de 08-11-1941 trata da abertura das propostas de concorrência pública para o serviço de transporte de carne-verde do Matadouro aos distribuidores.

2. - de 05-12-1960 a.

LIVROS DE EDITAIS.

1. - de 17-10-1941 a.

Um livro só. O primeiro edital data de 17 de outubro de $1941 \mathrm{e}$ trata da Concorrência Pública para o Serviço de transporte de Carne Verde.

\section{LIVROS DE PROTOCOLOS.}

\section{São vários Livros:}

Livro de Protocolos de Documentos para publicar.

1. - de 01-11-1969 a.

Livro de Protocolos de Ofícios Expedidos à Câmara Municipal.

1. - de 03-01-1964 a.

Livro de Protocolo para as Repartiçócs Municipais.

1. - de 01-11-1969 a.

Livro de Protocolos de Expedidos e outros Ofícios.

1. - de 01-11-1969 a.

Obs.: - Existem 12 volumes de Livros de protocolos antigos mas não organizados e portanto tornou-se difícil o arrolamento. A partir de 1959, o livro de protocolo foi desmembrado em vários, conforme os assuntos, como acima indicamos.

LIVROS DE TERMOS DE COMPROMISSOS DOS SRS. PREFEITOS E FUNCIONÁRIOS MUNICIPAIS.

\section{1. - de 02-01-1939 a 19-03-1956.}

O primeiro têrmo de compromisso data de 2 de janeiro de 1939 e foi feito pelo Sr. Antenor Vieira de Sá no cargo de Fiscal Arrecadador do distrito de Bastos.

2. - de 19-03-1956 a.

LIVROS DE CONCESSÕES PERPETUAS DOS CEMITÉRIOS LOCAIS.

São vários livros, dois livros para adultos e dois livros para menores, cada livro contém os números das sepulturas e o nome das pessoas enterradas. 
Obs.: - $\mathrm{O}$ atendimento por parte do Sr. Secretário e funcionários foi bom.

\section{III. - ARQUIVO DO CARTÓRIO DO REGISTRO CIVIL.}

Localização: Rua Caetés, 810.

Serventuário: Laércio Soares de Souza.

Data da instalação: 29 de agôsto de 1935.

$O$ arquivo contém:

\section{LIVROS DE NASCIMENTOS.}

São 63 volumes. O último em andamento. $O$ Livro $n^{\circ} 1$ vai de 27 de agôsto de 1935 a 29 de maio de 1939 , contém como primeiro registro o de Gessy Castilho Arisa, nascida em 26 de agôsto de 1935. Todos os livros possuem índice e há também fichário.

\section{LIVROS DE CASAMENTOS.}

São 41 volumes. O último em andamento. O livro $\mathrm{n}^{9} 1$ vai de 29 de agôsto de 1935 a 16 de junho de 1942, encontramos como primeiro registro de casamento o de João Batista Ribeiro com Cecília Castilho Arissa, datado de 29 de agôsto de 1935. Igualmente todos os livros possuem índice e fichário.

\section{LIVROS DE ÓBITOS.}

São 30 volumes. $O$ último em andamento. O livro $\mathrm{n}^{9} 1$ contém registros de 30 de agôsto de 1935 a 30 de dezembro de 1941. O primeiro óbito é de Leopoldina de Oliveira, datado de 30 de agôsto de 1935. Possui índice e fichário.

\section{LIVROS DE EDITAIS E PROCLAMAS.}

São 12 volumes, estando o último em andamento. O livro $\mathrm{n}^{\circ} 1$ vai de 2 de setembro de 1935 a 23 de dezembro de 1943. O primeiro proclama de casamento é de Benedito Gomes com Aparecida Vaz.

\section{LIVROS DE FEITOS.}

São 11 volumes. Dez arquivados e um em andamento.

\section{LIVROS DE VISITAS E CORREIÇÕES.}

Um: só volume, ainda em andamento, com a abertura datada de 3 de julho de 1945 . 


\section{LIVROS DE EMANCIPAÇÃO, INTERDIÇÃO E AUSENCIA.}

São dois volumes, estando um em andamento. O primeiro data de 18 de setembro de 1945 .

Obs.: - Todos os documentos acham-se em perfeito estado de conservação e o atendimento por parte do serventuário foi ótimo.

\section{IV. - ARQUIVOS DO CARTORIO DO Io OFICIO.}

Obs.: - Esse Cartório divide-se em duas partes: Parte Processual e $1^{\circ}$ Tabelionato.

Parte Processual:

Local: Palácio da Justiça (Praça da Bandeira).

Data de instalação: 3 de junho de 1945.

Serventuário: Jamil A. Dualibi.

LIVROS DE REGISTRO DE FEITOS.

São 8 volumes. O último em andamento. O primeiro livro vai de 3 de julho de 1945, suprimento de Idade de José Caram Neto, a 19 de março de 1952.

LIVROS DE ROL DOS CULPADOS.

São 5 volumes. O último em andamento.

LIVROS DE REGISTROS DE AVERBAÇÃO DE SURSIS.

São 2 volumes: O $1^{9}$ volume data de 5-11-1953 a 11-3-1968.

LIVROS DE OFICIOS PARA GABINETES DE IDENTIFICAÇÃO.

São 6 volumes.

LIVRO DE SELO PENITENCIÁRIO.

LIVROS DE CARGA E DESCARGA PARA AS PARTES

São 2 volumes.

Um volume. Pelas novas determinações da Justiça, êsse livro caiu em desuso.

LIVROS DE CARGA E DESCARGA PARA OS OFICIAIS DE JUSTIÇA.

São 5 (cinco) volumes.

LIVRO DE CARGA E DESCARGA PARA OS SRS. JUÍZES.

Um só volume, ainda em andamento. Sua abertura data de 28-6-1963. 


\section{LIVROS DE REGISTROS DE SENTENÇAS CRIMINAIS.}

São 4 volumes encardenados, um para ser encardenado. São postos em pastas encadernadas periòdicamente.

\section{LIVRO DE TERMO DE FIANÇAS.}

Um só volume em andamento. Aberto no dia 3 de junho de 1945 .

\section{LIVROS DE PROTOCOLOS DE AUDIENCIAS CRIMINAIS.}

São 10 volumes.

Obs. : - Essa parte do arquivo está muito mal organizada tornando impossível um levantamento mais detalhado dos livros. O atendimento por parte do funcionário foi bom.

$1^{9}$ Tabelionato: -

Instalação: - 24 de agôsto de 1935.

Local: - Rua Aimorés, 1.507.

\section{LIVROS DE ESCRITURAS.}

São 178 volumes, o último em andamento. O primeiro volume vai de 24 de agôsto de 1935 , a 05 de dezembro de 1938. A primeira escritura de venda e compra é de uma data de terreno, sendo vendedor João Moretti e compradora Joana Gimenes.

\section{LIVROS DE PROCURAÇÕES.}

São 108 volumes. O último em andamento. O primeiro volume vai de 24-08-1935 a 16-08-1938. O primeiro documento é de José Silva Júnior a Adolfo Hecht Filho.

Obs.: - Essa parte do arquivo esta muito bem organizada e o funcionário que nos atendeu foi muito amável.

\section{V. - ARQUIVO DO CARTÓRIO DO $2 \circ$ OFICIO.}

Local: - Rua Caetés n 798.

Instalação: -1945.

Serventuário: - Carlos Ferreira Damião.

$O$ arquivo contém: -

\section{LIVROS DE ESCRITURAS DE VENDA E COMPRA.}

São 49 volumes. O número foi aberto em 13 de julho de 1945, e vai até 19 de setembro de 1945. A primeira escritura tem com vendedor Aurea Rodrigues de Barros e compradora a firma Irmão Dias. 


\section{LIVROS DE PROCURAÇÃO.}

São 99 volumes. O último em andamento. O primeiro livro vai de 11 de junho de 1945 a 06 de julho de 1946, e na primeira procuração figura como outorgante $\%$ Sr: Julio Nery ao Dr. Sebastião Lins, datada de 11 de julho de 1945.

LIVROS DE REGISTROS DE FEITOS.

São 3 volumes. O último em andamento. O primeiro volume começa em 30 de julho de 1945 e traz o primeiro registro tendo como autor Aiko Hirai e réu Eiche Hirai.

\section{LTVROS DE ROL DOS CULPADOS.}

São 2 volumes. $\mathrm{O}$ primeiro registro é de Antonio Joaquim da Silva.

LIVROS DE REGISTROS DE AVERBAÇÃO DE SURSIS.

São 2 volumes. A abertura do primeiro volume é de 23 de maio de 1968.

\section{LIVROS DE CARGA E DESCARGA PARA AS PARTES.}

São 2 volumes. $O$ primeiro volume não foi encontrado, mas existe arquivado.

LIVROS DE CARGA E DESCARGA PARA OS OFICIAIS DE JUSTIÇA.

São 5 volumes. $O$ ínicio do primeiro volume data de 03 de fevereiro de 1945.

\section{LIVROS DE REGISTRO DE SENTENÇAS CRIMNNAIS.}

São 13 volumes. O primeiro volume encontrava-se arquivado, mas de difícil acesso, por isso não nos foi possível consultả-lo.

LIVROS DE REGISTRO DE PROCURAÇÕES.

São 23 volumes. $O$ primeiro volume tem sua abertura datada de 13 de julho de 1945.

LIVROS DE SUBSTABELECIMENTOS DE PROCURAÇÕES.

São 13 volumes. $O$ primeiro volume tem sua abertura em 27 de agôsto de 1946. 


\section{LIVROS DE ESCRITURAS DIVERSAS.}

São 26 volumes. $O$ primeiro volume tem sua abertura em 12 de julho de 1945.

Obs.: - $O$ atendimento por parte do sr. serventuário e funcionários foi bom.

VI. - ARQUIVO DE REGISTRO DE IMOVEIS E ANEXOS.

Localização: - Rua Caetés $n^{9} 1.121$.

Data da instalação: - 04 de julho de 1945.

Serventuário: - Claudionor Goss.

O Arquivo contém: -

LIVROS DE REGISTRO DE IMÓVEIS: -

de 1945 a 1969.

Livros de Protocolo.

3 volumes. Atualmente $1 \mathrm{C}$.

Livros de Inscrição Hipotecária.

2 volumes. Atualmente $2 \mathrm{~B}$.

Livros de Transcrição das Transmissōes.

10 volumes. Atualmente 30 .

Livros de Registros Diversos (4).

6 volumes.

Livros de Emissões de Debêntures (5).

1 volume (atualmente fora de uso).

Livros de Indicador Real (6).

1 volume.

Livros Indicador Pessoal (7). 1 volume.

Livros de Registro Especial (8).

1 volume.

Obs.: - Existe fichário dos livros.

LIVROS DE REGISTROS DE TÍTULOS E DOCUMENTOS.

de 1945 a 1969.

Livros de Registro Integral B.

4 volumes.

Livros de Registro Resumido C.

1 volume em andamento.

LIVRO DE PESSOA JURFDICA B 1.

1 volume em andamento. 
LIVROS DE OFICINAS IMPRESSORAS (B).

1 volume em andamento.

LIVRO DE CAUÇÃo.

1 volume.

LIVRO INDICADOR PESSOAL.

1 volume.

LIVROS DE REGISTROS DE FIRMAS.

São 6 volumes. O primeiro tem a abertura em data de 04 de julho de 1945. Esses livros perderam função, pois a partir de 1969, os registros são feitos na Junta Comercial em São Paulo.

LIVRO AUXILIAR.

De 1945 a 1969. Um volume, abertura em 04 de julho de 1945. Serve para registrar as separaçōes de bens.

LIVROS DE CÉDULA RURAL HIPOTECÁRIA.

São 2 volumes, o último em andamento. $\mathrm{O}$ primeiro volume tem sua abertura datada de 15 dé maio de 1967.

LIVROS DE PROTESTOS.

São 27 volumes. O primeiro volume tem a abertura em 04 de julho de 1945 .

\section{LIVRO DE CÉDULA INDUSTRIAL.}

Um só volume, com abertura em 22 de abril de 1969.

LIVRO DE REGISTRO ESPECIAL DE PROTESTOS.

Um só volume com abertura de 08 de setembro de 1955, não contém nenhum registro.

Obs.: - Existe fichário dos livros de protestos.

LIVRO DE REGISTRO DE NOTIFICAÇõES EXPEDIDAS PELA COMISSÃO GERAL DE INVESTIGAÇÃO.

Um só volume, com abertura de 01 de agôsto de 1969. Possui indice.

Obs.: - $\mathrm{O}$ atendimento por parte do sr. serventuário foi btimo. 
VII. - ARQUIVO DO CARTORIO DISTRIBUIDOR, CONTADOR, PARTIDOR E AVALIADOR JUDICIAL EM CASOS PREVISTOS:

Local: - Palácio da Justiça (Praça da Bandeira).

Data da instalação: - 1945.

Serventuário: - Adelino Mendes Melges.

LIVROS DE DISTRIBUIÇÃO.

Distribuições Civis.

São 5 volumes. O primeiro volume vai de 26 de julho de 1945 a 09 de dezembro de 1952 .

Distribuiçōes Criminais.

São 3 volumes. O primeiro volume vai de 07 de agôsto de 1945 a 12 de dezembro de 1953.

Distribuições Executivo-Fiscais.

São 6 volumes. O primeiro volume vai de 23 de julho de 1945 a $1^{\circ}$ de junho de 1949.

Distribuiçōes Comerciais.

São 9. volumes. O primeiro volume vai de 23 de julho de 1945 a 12 de junho de 1949.

Distribuiçōes de Escrituras.

São 7 volumes. O primeiro volume vai de 23 de julho de 1945 a 06 de fevereiro de 1947 .

Distribuições de Carga de Autos e Feitos.

São 6 volumes. O primeiro volume vai de 18 de janeiro de 1963 a 26 de julho de 1964.

Livro Indice Geral, Civil, Crimes e Fiscal.

São 5 volumes.

LIVRO DE VISITAS E CORREIÇÕES.

Um só volume, com abertura no dia 28 de novembro de 1952.

LIVRO DE HOMOLUGAÇÃO JUUDICIAL DE ACÔRDO.

Um só volume, com início em 04 de outubro de 1967.

LIVRO DE RECLAMAÇÕES TRABALHISTAS.

Um só volụme, com abertura em 30 de julho de 1945.

LIVROS DE INQUERITO POLICIAL.

São 2 volumes. O primeiro vai de 30 de setembro de 1961 a 12 de maio de 1964. 
Obs.: - Ele serve como fonte para futuros processos crimes.

Obs.: - O Cartório possui fichário de distribuição criminais e pastas contendo segundas vias de certidões; avaliação, de partliha, contas de custas. Os livros se encontram em bom estado de conservação, e $o$ atendimento por parte do funcionário foi bom.

\section{VIII. - ARQUIVO DA PAROQUIA DE SÃO PEDRO.}

Localização: - Praça da Bandeira.

Instalação: - 29 de novembro de 1936.

Vigário atual: - Monsenhor Afonso Hafner.

0 arquivo contém:

\section{LIVROS DO TOMBÓ.}

São 2 volumes.

1. - de 29-11-1936 a 30-08-1953.

O primeiro assentamento data de 29 de novembro de 1936 , é o têrmo de posse do Pe. Gaspar Aguiló Cortés, como vigário da paróquia.

$$
\text { 2. - de 03-09-1953 a. }
$$

\section{LIVROS DE BATIZADOS.}

São 32 volumes. O primeiro volume compreende os anos de 1936 a 1938, sendo o primeiro registro de Juarez, nascido em 30 de setembro de 1936, filho de Juvenço Cavalcante e Diva Cavalcante, sendo vigário o Pe. Gaspar Aguiló Cortés.

Obs.: Existem alguns livros em duplicata que ainda não foram enviados à Cúria Metropolitana.

\section{LIVROS DE CASAMENTOS.}

São 12 volumes. O número um vai de 1936 a 1945 e o primeiro registro é o do casamento de Emilio Silva com Joaquina Ferreira, datado de 11 de dezembro de 1936, sendo vigário o Pe. Gaspar Aguiló Cortés.

Obs.: - Existem livros em duplicata: que não foram ainda enviados à Cúria Metropolitana.

\section{LIVROS DE ÓBITOS.}

São 2 volumes. O primeiro volume registra assentamentos de 1936 a 1950 e o primeiro registro de óbito é o de Euclides, filho de Domingos Pinheiro e de Ida Lorenzete, datado de 18 de janeiro de 1963, sendo vigário o Pe: Gaspar Aguiló Cortés. 


\section{LIVROS DE CRISMAS.}

São 2 volumes. O primeiro volume vai de 1937 e 1939, e o primeiro crisma é de Ana, filha de João Silva e Maria da Conceição, datado de 20 de outubro de 1937, sendo vigário o Pe. Gaspar Aguiló Cortés.

Obs.: - $\mathrm{O}$ atendimento por parte do vigário auxiliar, Pe. Tito Marega, foi o melhor possivel.

\section{IX. - ARQUIVO DA PAROQUIA DE NOSSA SENHORA AUXILIADORA.}

Localização: - Praça Dom Bosco.

Instalação: - 16 de fevereiro de 1955.

Vigário atual: - Pe. Ernesto Tessarolo.

\section{LIVRO DO TOMBO.}

Um só volume, estando ainda em andamento. Iniciou-se em 1955, e o primeiro assentamento registra a criação da Paróquia, datado de 11 de fevereiro de 1955.

\section{LIVROS DE BATIZADOS.}

O primeiro volume compreende aos anos de 1955 a 1957, e o primeiro registro é o do batizado de Sônia Maria, filha de Leandro Cunha, e Odila Sanchez Cunha, datado de 16 de janeiro de 1955, assinado pelo vigário, o Pe. João Pian.

Obs.: - Foi utilizado o livro duplicata, pois não se encontrou o original, aliás, existem todos os livros duplicatas que não foram ainda enviados à Cúria Metropolitana.

Nesse primeiro assentamento, a data é anterior à instalação da paróquia, pensamos que seja êrro da pessoa que transcreveu no livro. Pois os assentamentos seguintes datam de fevereiro.

\section{LIVROS DE CASAMENTOS.}

São 4 volumes. O primeiro volume vai de 19535 a 1961, e registra - primeiro casamento que é de Francisco de Luca com Antonia Neodilha de Luca, datado de 20 de fevereiro de 1955, sendo vigário Pe. João Pian.

Obs.: - Existem todos os livros duplicatas que também não foram enviados à Cúria Metropolitana. 


\section{LIVROS DE ÓBITOS.}

Um só volume. O primeiro registro é o da morte de Rosa Januário, datado de 06 de janeiro de 1961, sendo vigário o Pe. Tomaz Ghirardelli.

Obs.: - Os livros se encontram em ótimo estado de conservação, e o atendimento por parte do vigário foi ótimo.

\section{X. - ARQUIVO DA PAROQUIA DE SAO JUDAS TADEU.}

Local: - Praça João XXIII.

Instalação: - 13 de maio de 1962.

Vigário atual: - Pe. Dionísio Hermoso.

\section{LIVRO DO TOMBO.}

Um só volume, com início em 07 de abril de 1962, fala da instalação da paróquia, sendo vigário o Pe. Pedro Cometti.

LIVRO DE BATIZADOS.

Um só volume, com início em 07 de abril de 1963, sendo o primeiro registro de Maria de Fátima, filha de Inácio de Jesus Coelho e Maria dos Santos Coelho, sendo vigário o Pe. Nicolau Hammer.

\section{LIVRO DE CASAMENTOS.}

Um só volume. O primeiro registro é de $1^{p}$ de março de 1963 , sendo de Inácio da Cruz Coelho com Maria dos Santos, e o vigário era o Pe. Nicolau Hammer.

Obs. : - Os livros estão em bom estado de conservação e o atendimento por partedo sr. vigário foi ótimo.

\section{XI. - ARQUIVO DE JORNAIS.}

FOLHA DO POVO.

Localização: - Rua Guaranis, 536.

Fundador e Diretor: - Waldir de Souza.

Data da Fundação: - 19-08-1937 (3a: fase).

Iniciado em $1^{9}$ de agôsto de 1967, os jornais são encadernados periòdicamente e estão em bom estado de conservação. $O$ jornal encontra-se em uma terceira fase, mas das fases anteriores não se encontrou exemplares na redação e nem em coleçōes particulares. 0 jornal é diário e vespertino.

Obs.: - $\mathrm{O}$ atendimento por parte do funcionário foi bom. 


\section{JORNAL DE TUPA.}

Localização: - Av. Tamoios $n^{\circ}$ 1.365:

Fundador: - Antenor de Barros Leite.

Diretor atual: - Miguel Amador Polo.

Data da fundação: - 30-10-1944.

O jornal é diário e vespertino. Os jornais se encontram na sua grande parte encadernados e em bom estado de conservação.

Obs.: - $\mathrm{O}$ atendimento por parte dos funcionários foi bom.

JORNAL DA REGIX̃o.

Localização: - Rua Mandaguariș $n^{\circ} 337$.

Fundador e Diretor: - Aleixo Corrêa Neto.

Data da fundação: -09 de julho de 1960.

O jornal é trissemanário. Desde a fundação, os jornais são encadernados e estão em bom estaḍo de conservação,- encontrando-se atualmente no $n^{9}$ 743. Em 1968, o jornal deixou de circular e foi substituído pelo "Alta Paulista" que durou apenas. um ano.

Obs.: - $\mathrm{O}$ atendimento por parte do. diretor do jornal foi bom.

\section{XII. - ARQUIVO DA AGENCIA MUNICIPAL DE ESTA- TISTICA .}

Agente: - Ramon Barrionuevo.

Instalação: -1950 .

Localização: - Rua Caingangs $n^{\circ} 337$.

Possui na Biblioteca:

1. - Enciclopédia dos Municípios Brasileiros:

2. - Registro Industrial.

3. - Registro Civil.

4. - História de Tupã.

5. - Fôlha de atualização do Cadastro (1 esumo do que há demais importante na cidade).

6. - Caderno de Pésquuisà de Prodüção Agrícola e Pecuária.

7. - Aspecto gerais do município (feitos' periòdicamente).

8. - Estatística Demográfica e estimativas intermediárias.

9. - Mapas da cidade e municipio (atualizados periòdicamente).

10, - Resenhas informativas sôbre pecuária, agricultura, movimento sindical.

11. - O material é de uso privativo da agência e está guardado em pastas.

Obs.: $O$ atendimento por parte do agente foi bom. 


\section{XIII. - MUSEU HISTORICO E PEDAGOGICO "INDIA VANUIRE"'.}

Localização: - Av. Tamoios, 1.358.

Instalação definitiva: - 27 de março de 1968.

Presidente atual: - Nair Chedini (1969).

O museu possui Seções Indígenas, de Armas, pequena Biblioteca de assuntos indígenas, Seção de Fotografias Históricas de Tupã.

Peças de louças e objetos pessoais do fundador de Tupã, sr. Luiz de Souza Leão. Possui também Seção de Jornais contendo jornais da época da Revolução Constitucionalista de 1932 de São Paulo, além de jornais do município, como o Jornal de. Tupã, que se encontram encadernados dos anos de 1947 a 1955. Além dessas há também as seções de moedas a aves.

Obs.: - Os objetos se encontram em bom estado de conservação e o atendimento por parte dos funcionários, sr. José Manzano e dona Nair Corrêa Vieira, fói bom.

\section{ESTABELECIMENTOS DE CRÉDITO.}

A rêde bancária é constituída de onze agências dos seguintes bancos: - Bandeirantes do Comércio, Brasileiro de Descontos, de Minas Gerais, do Brasil, do Commércio e Indústria de São Paulo, do Estado de São Paulo, Econômico da Bahia, Mercantil de São Paulo, União de Bancos Brasileiro, Noroeste do Estado de São Paulo e Português do Brasil, além de duas agências das Caixas Econômicas (Federal e Estadual).

\section{ASSOCIAÇÕES DESPORTIVAS E RECREATIVAS.}

Tupã possui clubes culturais, recreativos e desportivos, num total de vinte, destacando-se entre êles: - a Associação Cultural de Tupã, o Centro Cultural Mário de Andrade, o Tupã Base-Ball Clube, - Clube Marajoara (o mais antigo), o Tupã Country Clube, o Tupã Tenis Clube e o Clube de Regatas Paulista.

\section{ESTABELECIMENTOS DE ENSINO}

Tupã possui 81 unidades escolares de ensno primário, 8 de ensino médio è uma de ensino superior. Entre os estabelecimentos de ensino médio, destäcam-se o Instituto de Educação India Vanuire, o Colégio Dom Bosco, o: Ginásio Industrial Estadual de Tupã, e o Ginásio "e Escola Normal Livre Nossa Senhora Auxiliadora.

$O$ ensino superior é representado pela Faculdade de Filosofia, Ciências. e Letras, entidade particular que ministra os cursos de Pedagogia, Letras, História e Matemática. 


\section{BRASÃO DE ARMAS.}

A seguir, transcrevemos a lei $n^{\circ} 66$, de 6 de abril de 1959, que institui o Brasão de Armas de Tupã:

"Alonso Carvalho Braga, Prefeito Municipal de Tupã, usando das atribuições que the são conferidas por lei,

Faço saber que a Câmara Municipal decreta e eu promulgo a seguinte lei:

Art. $1^{\circ}$ - Fica instituido o Brasão de Armas de Tupã, cuja descrição na terminologia heráldica é a seguinte: De azul, cabeça de índio de frente, de carnação com cabelos compridos de sua côr e fota estreita de prata, a cabeça bordada de chamas de vermelho das quais saem quatro raios em aspas de ouro. Timbre: corea mural de ouro.

Art. $2^{\circ}$ - O Brasão quando reproduzido monocrònicamente como suc̀ede comumente nos papéis oficiais das repartiçōes públicas, tera suas côres segundo as respectivas convençōes heráldicas, universalmente adotadas.

Art. $3^{\circ}-$ A publicação desta lei no órgão oficial do município será feita acompanhada apenas do anexo 2 (art. 2) devendo o Executivo dentro de 90 dias a contar da data de sua publicação, reproduzí-las em folheto, com os seus dois anexos (art. $1^{\circ}$ e $2 .^{\circ}$ ) a fim de distribu-lo a tôdas as escolas, repartiçōes, podendo ainda ser distribuído ou vendido ao público pela Biblioteca Municipal.

Art. $4^{9}$ - Esta Lei entrará em vigor na data de sua publicação, revogadas as disposiçōes em contrário.

Prefeitura Municipal de Tupã, 6 de abril de 1949.

Alonso Carvalho Braga

Prefeito Municipal

Nelson de Camargo Penteado

Secretário".

Obs.: - Os dados gerais sôbre o Município de Tupã foram retirados de uma monografia do Instituto Brasileiro de Geografia e Estatística. A única publicação que encontramos sôbre Tupã foi um livreto denominado "A Fundaçāo de Tupan" de Luiz de Souza Leão, que por sinal é seu fundador e ainda vive, morando na cidade. A obra é um relato dos fatos relacionados com a fundação da cidade e seus primeiros anos de vida. Como curiosidade a ser visitada ou para um estudo por parte de algum especialista, existe a poucos quilômetros da cidade uma aldeia de índios Caingangues, do Serviço de Proteção ao fndio. 